\title{
Cancer treatment in the last 6 months of life: when inaction can outperform action
}

\author{
Bishal Gyawali ${ }^{1}$ and Saroj Niraula ${ }^{2}$ \\ 1Program on Regulation, Therapeutics and Law (PORTAL), Division of Pharmacoepidemiology and Pharmacoeconomics, Brigham and Women's Hospital, \\ Harvard Medical School, Boston, MA 02120, USA \\ ${ }^{2}$ Department of Medical Oncology and Hematology, University of Manitoba and Cancer Care Manitoba, Winnipeg R2H 2A6, Canada
}

Correspondence to: Bishal Gyawali. Email: bg.bishalgyawali@gmail.com; Twitter: @oncology_bg

\begin{abstract}
When an investigational anticancer drug is being tested, demonstration of improvement in overall survival (OS) will generally lead to regulatory approval. However, the value that improvement in OS adds to patients' lives is guided largely by the context of the improvement and accompanying trade-offs. For example, when a patient's life expectancy is less than 6 months, many oncologists will not embark on any active cancer treatments. However, multiple new anticancer drugs have been approved recently after being tested in end-stage cancer patients and demonstrating median OS in the experimental arm close to 6 months. Such practice, particularly when the treatment is also accompanied by serious toxicities and cost, can undermine a peaceful life-death transition. In this commentary, we review regulatory approvals in the last 5 years and the ethical considerations involved in testing active cancer treatment in terminal cancer patients.
\end{abstract}

Keywords: end of life, financial toxicity, overall survival, serious adverse events, fatal adverse events

ecancer 2018, 12:826 https://doi.org/10.3332/ecancer.2018.826

Copyright: (c) the authors; licensee ecancermedicalscience. This is an Open Access article distributed under the terms of the Creative Commons Attribution License (http://creativecommons.org/licenses/by/3.0), which permits unrestricted use, distribution, and reproduction in any medium, provided the original work is properly cited. 
Recently, a fully human IgG4 monoclonal antibody inhibitor of programmed death-1 (PD-1), nivolumab (Opdivo), was reported to show a statistically significant improvement in overall survival (OS) compared to placebo in terminal gastric or gastro-oesophageal junction cancers [1]. Although the 1 month improvement in survival observed in this trial is a real gain, the trial also showed that the median OS, regardless of the randomisation arm, was less than 6 months. Although formal measures of quality of life were not presented in the trial report, potentially debilitating toxicities, treatment-related deaths and drug discontinuations were higher in the experimental arm. Nivolumab is also a highly expensive drug.

Many oncologists will not recommend active cancer treatment when they recognise that their patients are in the last few months of life [2-4]. Cancer patients will have usually undergone a series of invasive treatments including surgery, radiotherapy and drug therapy during the course of their disease. These limited last few months are precious for cancer patients and their families, and when patients are on active therapy, it will lead to time being spent visiting treatment rooms and enduring toxic effects of cancer treatments. The financial toxicity of high-cost therapies administered during this time can be another source of stress for patients and their families.

\section{Why do we continue prescribing drugs in the last 6 months?}

One obvious answer is that we do not know how best to predict survival-physicians are known to be particularly bad at this and they tend to be unrealistically optimistic [5]. Physicians and patients tend to have exaggerated confidence in the benefits of drugs regardless of the disease setting, despite many studies confirming the futility of chemotherapy in the last 6 months of life [3,6,7]. Furthermore, many patients receiving chemotherapy for incurable cancers do not realise that chemotherapy is unlikely to be curative, which can lead to increased desire for aggressive treatments and high threshold of acceptable toxicities [8]. Drug websites that patients use to seek information on cancer therapies can provide overestimates of drugs' benefits and downplay their harms [9].

\section{Last 5 years of cancer drugs approval}

After the publication of the ATTRACTION trial [1], we explored systematically the frequency of drug approvals when OS is less than 6 months. Since United States Food and Drug Administration (FDA) approval of a drug often signals that other regulators should approve the drug in their countries, we examined data available publicly on the FDA's website [10] and checked survival data for cancer drugs approved for the treatment of advanced or metastatic solid cancers between January 2012 and December 2016. In this time period, there were a total of 70 drugs approved, including new indications for drugs already on the market. We found three cancer drugs (4.3\%) approved during this timeframe that were tested in a population which had a median OS of 6.5 months or fewer with the drug (Table 1). This is likely an underestimation of drugs meeting this criteria, since patient survival in routine practice is inferior to that observed in the controlled setting of clinical trials [11].

The three drugs were regorafenib (Stivarga) for later line treatment of metastatic colorectal cancer, ramucirumab (Cyramza) for the second line treatment of metastatic gastric or gastro-oesophageal cancer and liposomal irinotecan (Onivyde) for the second line treatment of metastatic pancreatic cancer. Coincidentally, all these three drugs, as well as the trial of nivolumab in gastric cancer mentioned above, are for cancers of the gastrointestinal system. For the nivolumab example, it may well be argued that the median doesn't adequately capture the benefit with PD-1 drugs [20]. However, the same cannot be argued for these three drugs, which are not immunotherapies.

The additional survival benefit stemming from the use of these drugs as compared to the control arm was less than 2 months (1.4-1.9 months). Thus, the trade-off for efficacy with these drugs observed in the trials was between 3.8 and 5.0 months of drug-free life versus 5.2-6.4 months of life with drugs. When these drugs are considered for use by cancer patients and their oncologists, these survival gains should be balanced against the potential clinical toxicities from these drugs, including the financial toxicities to the patient and family.

\section{How toxic are these agents?}

Regorafenib, ramucirumab and liposomal irinotecan are associated with a variety of toxicities, including substantially increased risks of serious and fatal adverse events (FAEs). Patients who are in the last 6 months of their lives considering the use of these drugs should, therefore, be adequately informed that their anticancer agents could put them at risk for serious adverse events (SAEs) including death in the hope of prolonging life by less than 2 months at the median. 


\section{How expensive are these agents?}

Despite providing minimal benefit and being associated with various potentially fatal toxicities, these drugs cost more than $\$ 9500$ every month in the US. These costs may be borne to differing degrees by the patients themselves, depending on their insurance status. Since many cancer patients are on public insurance programs in the US such as Medicare and Medicaid, it is also worth considering whether it is sustainable at the societal level to pay over $\$ 9500$ every month for a drug that extends survival by less than 2 months for patients who are in the last 6 months of their lives. Resources are finite: spending in such low value drugs can lead to compromises in access to other life-saving treatments, or in valuable societal priorities such as childhood education [12, 13].

\section{Role of the media in communication}

Representation of cancer drugs in the media can influence peoples' perceptions of treatment, and particular slogans or 'buzz-words' can be particularly consequential for patients dealing with serious illnesses. For example, 'war' or 'fight' is a common metaphor used to describe a patient's journey through cancer [14]. This makes cancer patients feel as if the outcomes of cancer, at least in part, rely on their personal efforts; and as a result, patients subject themselves to unjustifiable toxicities in an effort to 'win the battle' against cancer [15]. This encourages overuse of active cancer treatments past the point of futility.

Table 1. The survival gains, toxicity profiles and cost of three anticancer drugs with an OS of 6.5 months or less.

\begin{tabular}{|c|c|c|c|c|c|c|c|c|c|c|c|c|}
\hline Drug & $\begin{array}{l}\text { Study } \\
\text { name }\end{array}$ & $\begin{array}{c}\text { Year of } \\
\text { FDA } \\
\text { approval }\end{array}$ & Indication & $\begin{array}{c}\text { Survival } \\
\text { with the } \\
\text { drug }\end{array}$ & $\begin{array}{l}\text { Survival } \\
\text { in control } \\
\text { arm (con- } \\
\text { trol agent) }\end{array}$ & $\begin{array}{c}\text { Gain in } \\
\text { survival }\end{array}$ & $\begin{array}{c}\text { SAE } \\
\text { (drug) }\end{array}$ & $\begin{array}{c}\mathrm{SAE} \\
\text { (control) }\end{array}$ & $\begin{array}{c}\text { FAE } \\
\text { (drug) }\end{array}$ & $\begin{array}{c}\text { FAE } \\
\text { (control) }\end{array}$ & $\begin{array}{c}\text { Cost of } \\
1 \text { month } \\
\text { treatment } \\
\text { (WAC) }\end{array}$ & $\begin{array}{l}\text { Reference } \\
\text { (Pubmed } \\
\text { ID) }\end{array}$ \\
\hline Regorafenib & CORRECT & 2012 & $\begin{array}{l}\text { Last line } \\
\text { treatment of } \\
\text { metastatic } \\
\text { colorectal } \\
\text { cancer }\end{array}$ & 6.4 & $\begin{array}{c}5.0 \\
\text { (placebo) }\end{array}$ & 1.4 & $\begin{array}{l}219 / 500 \\
(43.8 \%)\end{array}$ & $\begin{array}{l}100 / 253 \\
(39.5 \%)\end{array}$ & $\begin{array}{c}8 / 500 \\
(1.6 \%)\end{array}$ & $\begin{array}{c}3 / 253 \\
(1.2 \%)\end{array}$ & $\$ 9919$ & 23177514 \\
\hline Ramucirumab & REGARD & 2014 & $\begin{array}{l}\text { Second line } \\
\text { treatment of } \\
\text { metastatic } \\
\text { gastric or } \\
\text { gastro- } \\
\text { oesophageal } \\
\text { junction } \\
\text { cancer }\end{array}$ & 5.2 & $\begin{array}{c}3.8 \\
\text { (placebo) }\end{array}$ & 1.4 & NR & NR & \begin{tabular}{|l|}
$5 / 236$ \\
$(2.1 \%)$
\end{tabular} & $\begin{array}{c}2 / 115 \\
(1.7 \%)\end{array}$ & $\$ 13,093$ & 24094768 \\
\hline $\begin{array}{l}\text { Liposomal } \\
\text { Irinotecan* }\end{array}$ & NAPOLI-1 & 2015 & $\begin{array}{l}\text { Second line } \\
\text { treatment of } \\
\text { metastatic } \\
\text { pancreatic } \\
\text { cancer }\end{array}$ & 6.1 & $\begin{array}{c}4.2 \text { (fluo- } \\
\text { rouracil + } \\
\text { folinic acid) }\end{array}$ & 1.9 & $\begin{array}{l}146 / 264 \\
(55.3 \%)\end{array}$ & $\begin{array}{c}60 / 134 \\
(44.8 \%)\end{array}$ & $\begin{array}{c}5 / 264 \\
(1.9 \%)\end{array}$ & $\begin{array}{c}0 / 134 \\
(0 \%)\end{array}$ & $\$ 9720$ & 26615328 \\
\hline
\end{tabular}

Common adverse events (with incidence $>10 \%$ in clinical trials) with the three drugs that provide a survival of 6 months (survival benefit of $<2$ months).

1. Regorafenib: Fatigue, hand-foot skin reaction, diarrhoea, anorexia, hypertension, oral mucositis, rashes, nausea, weight loss, fever, thrombocytopenia.

2. Ramucirumab: Fatigue, abdominal pain, loss of appetite, vomiting, constipation, anaemia, dysphagia.

3. Nanoliposomal Irinotecan: Diarrhoea, vomiting, nausea, loss of appetite, fatigue, neutropenia, aneamia, hypokalaemia

*there were three arms in NAPOLI-1 trial: liposomal irionotecan alone (1), liposomal irinotecan +fluorouracil +folinic acid (2) and fluorouracil +folinic acid (3). Only arm 2 was shown superior and survival data corresponds to comparison between arms 2 and 3 . For safety data, arms 1 and 2 are combined WAC = wholesale acquisition costs. These were obtained from the list available at https://www.mskcc.org/sites/default/files/node/25097/

documents/120915-drug-costs-table.pdf

For liposomal irinotecan, the WAC was calculated from the information available at: http://secure.medicalletter.org/w1496e

$\mathrm{NR}=$ not reported 
We need to do a better job of communicating the realities of cancer diagnoses to patients. For example, one group of authors recently proposed a new outcome measure of 'days spent at home in the last 6 months of life' to gauge the effectiveness of an investigational therapy [16]. Should we go a step further and consider whether regulatory agencies should approve drugs that provide a statistically significant OS benefit in a population of patients with an OS (not benefit) of 6 months or less?

\section{Are we negotiating goals of treatment effectively?}

The ultimate goal of a medical intervention is to improve the duration or some measure of quality of life. Active interventions may be associated with a better sense of accomplishment for physicians, and perhaps for patients too, so we can fail to recognise that inactions may sometimes yield better outcomes than actions. When cure is not possible, prognosis is guarded severely, and treatments are accompanied by substantial trade-offs, conversations about the goals of treatment with the patients become paramount. Patients usually have an unrealistic perception of their disease stage; one survey found that only a small minority of patients in the terminal stage of their disease is aware of their prognosis [17]. By contrast, patients who discuss the prognosis of their disease with oncologists come to have a better understanding of the terminal nature of their illness [17]. The oncology community should not accept that a substantial proportion of patients have a survival expectation different from their oncologist's [18]. Educating patients with respect to what is reasonable to hope for including any uncertainties, discussing potential toxicities of treatment and accommodating cultural and personal priorities will have crucial roles in refining patients' goals from treatment.

\section{Solution}

The implications of the decision to treat a terminally ill patient are multidimensional, but the ultimate goal should be to help patients with a peaceful life-death transition. To that end, education and training of oncologists on end of life care, managing expectations of patients and communication skills are important, as is the role of the media in promoting the importance and complexities of navigating quality end of life care and discouraging the 'war' metaphor for cancer. It is also the case that prescribing drugs in the last 6 months of life constitutes a substantial proportion of total healthcare costs, and we may be able to avoid some of these costs if patients better understand the benefit/ risk trade-off offered by anticancer drugs tested in this population [19].

\section{References}

1. Kang Y-K, Boku N, and Satoh $\mathrm{T}$, et al (2017) Nivolumab in patients with advanced gastric or gastro-oesophageal junction cancer refractory to, or intolerant of, at least two previous chemotherapy regimens (ONO-4538-12, ATTRACTION-2): a randomised, double-blind, placebo-controlled, phase 3 trial Lancet 390 2461-2471 https://doi.org/10.1016/S0140-6736(17)31827-5 PMID: 28993052

2. Blanke CD and Fromme EK (2015) Chemotherapy near the end of life: first—and third and fourth (line)—do no harm JAMA Oncol 1 785-786 https://doi.org/10.1001/jamaoncol.2015.2379 PMID: 26203585

3. Prigerson HG, Bao Y, and Shah MA, et al (2015) Chemotherapy use, performance status, and quality of life at the end of life JAMA Oncol 1(6) 778-784 https://doi.org/10.1001/jamaoncol.2015.2378 PMID: 26203912 PMCID: 4828728

4. Wennberg JE, Fisher ES, and Stukel TA, et al (2004) Use of hospitals, physician visits, and hospice care during last six months of life among cohorts loyal to highly respected hospitals in the United States BMJ 328607 https://doi.org/10.1136/bmj.328.7440.607 PMID: 15016692 PMCID: $\underline{381130}$

5. Christakis NA and Lamont EB (2000) Extent and determinants of error in physicians' prognoses in terminally ill patients: prospective cohort study West $J$ Med 172 310-313 https://doi.org/10.1136/ewjm.172.5.310 
6. Kao S, Shafiq J, and Vardy J, et al (2009) Use of chemotherapy at end of life in oncology patients Ann Oncol $201555-1559$ https://doi.org/10.1093/annonc/mdp027 PMID: 19468033

7. Matsuyama R, Reddy S, and Smith TJ (2006) Why do patients choose chemotherapy near the end of life? a review of the perspective of those facing death from cancer J Clin Oncol 24 3490-3496 https://doi.org/10.1200/JC0.2005.03.6236 PMID: 16849766

8. Weeks JC, Catalano PJ, and Cronin A, et al (2012) Patients' expectations about effects of chemotherapy for advanced cancer $N$ Engl J Med 367 1616-1625 https://doi.org/10.1056/NEJMoa1204410 PMID: 23094723 PMCID: 3613151

9. Sullivan HW, Aikin KJ, and Squiers LB (2016) Quantitative information on oncology prescription drug websites $J$ Cancer Educ 33 371-374 https://doi.org/10.1007/s13187-016-1107-1 PMID: 27589969 PMCID: $\underline{5334459}$

10. [http://www.fda.gov/Drugs/InformationOnDrugs/ApprovedDrugs/ucm279174.htm] Date accessed: 18/10/2017

11. Mailankody $S$ and Prasad $V(2016)$ Overall survival in cancer drug trials as a new surrogate end point for overall survival in the real world JAMA Oncol 3(7) 889-890 https://doi.org/10.1001/jamaoncol.2016.5296 PMID: 27892992

12. Gyawali B and Sullivan R (2017) Economics of cancer medicines: for whose benefit? New Bioeth 23 95-104 https://doi.org/10.10 80/20502877.2017.1314885 PMID: 28517989

13. Woolf SH and Johnson RE (2005) The break-even point: when medical advances are less important than improving the fidelity with which they are delivered Ann Fam Med 3 545-552 https://doi.org/10.1370/afm.406 PMID: 16338919 PMCID: 1466946

14. Hanahan D (2014) Rethinking the war on cancer Lancet 383 558-563 https://doi.org/10.1016/S0140-6736(13)62226-6

15. McCartney M (2014) The fight is on: military metaphors for cancer may harm patients BMJ 349 g5155 https://doi.org/10.1136/ bmj.g5155 PMID: 25128488

16. Groff AC, Colla CH, and Lee TH (2016) Days spent at home-a patient-centered goal and outcome N Engl J Med 375 1610-1612 https://doi.org/10.1056/NEJMp1607206 PMID: 27783911

17. Epstein AS, Prigerson HG, and O'Reilly EM, et al (2016) Discussions of life expectancy and changes in illness understanding in patients with advanced cancer J Clin Oncol 34 2398-2403 https://doi.org/10.1200/JCO.2015.63.6696 PMID: 27217454 PMCID: $\underline{4981977}$

18. Gramling R, Fiscella K, and Xing G, et al (2016) Determinants of patient-oncologist prognostic discordance in advanced cancer JAMA Oncol 2 1421-1426 PMID: 27415765

19. Gyawali B (2017) Low-value practices in oncology contributing to financial toxicity Ecancermedicalscience 11727 https://doi. org/10.3332/ecancer.2017.727 PMID: $\underline{28386297}$ PMCID: $\underline{5365336}$

20. Hoering $\mathrm{A}$, Durie $\mathrm{B}$, and Wang $\mathrm{H}$, et al (2017) End points and statistical considerations in immuno-oncology trials: impact on multiple myeloma Future Oncol 13 1181-1193 https://doi.org/10.2217/fon-2016-0504 PMID: 28395525 PMCID: $\underline{5705823}$ 